\title{
Patients with systemic lupus erythematosus have impaired strain and vascular function which is incremental to that caused by traditional risk factors: insights from Cardiovascular Magnetic Resonance
}

\author{
Ntobeko A Ntusi ${ }^{*}$, Jane M Francis ${ }^{1}$, Paul M Matthews ${ }^{2}$, Paul B Wordsworth ${ }^{3}$, Stefan Neubauer ${ }^{1}$, \\ Theodoros Karamitsos ${ }^{1}$ \\ From 16th Annual SCMR Scientific Sessions \\ San Francisco, CA, USA. 31 January - 3 February 2013
}

\section{Background}

Systemic lupus erythematosus (SLE) is a systemic autoimmune disorder that commonly affects the heart. The impact of SLE on the heart is a 7 to 9 times greater incidence of cardiovascular disease (CVD) in SLE patients compared to healthy controls. Moreover, female patients with SLE between 35 and 44 years old have an incidence of myocardial infarction over 50 times greater than that observed in the Framingham cohort. The exact cause of this excess CVD burden in SLE is poorly understood, but is thought to be multi-factorial. Cardiovascular magnetic resonance (CMR) has the capacity of simultaneously assessing non-invasively cardiac function, altered vascular distensibility, myocardial strain and fibrosis. The purpose of this study was to assess cardiac and vascular function and myocardial strain in patients with SLE and to determine their relation to the presence of cardiovascular risk factors (CVRFs) and SLE disease duration.

\section{Methods}

11 SLE patients with no CVRFs (11 female, mean age 37 \pm 7 ), 19 SLE patients with CVRFs (18 female, mean age $47 \pm 11$ ), 39 normal controls (39 female, mean age 45 \pm 12 ), and 11 controls with CVRFs (11 female, mean age $52 \pm 9$ ), underwent CMR at 1.5 Tesla. All patients with previously known CVD were excluded. CVRFs, disease activity index and duration of disease were

${ }^{1}$ Cardiovascular Medicine, University of Oxford, Oxford, UK

Full list of author information is available at the end of the article recorded for each subject. Biventricular volumes and function, LGE, myocardial strain and vascular function were assessed by CMR. Aortic distensibility and pulse wave velocity (PWV) were measured in the ascending aorta, proximal descending aorta and distal descending aorta.

\section{Results}

There were no differences in left ventricular (LV) volumes and LV ejection fraction between the 4 groups (Table 1 ). SLE patients with CVRFs showed the greatest reduction in mid short axis circumferential systolic strain, peak diastolic strain rate, and vascular indices. SLE patients without CVRFs showed a similar degree of vascular dysfunction and deformational abnormality as controls with CVRFs. Aortic distensibility $(\mathrm{Rs}=-0.59, \mathrm{p}<0.001)$ and total pulse wave velocity $(R s=0.29, p=0.01)$ correlated with SLE disease duration (Table 2).

\section{Conclusions}

Evidence of impaired circumferential systolic strain and vascular function in SLE is demonstrated on CMR assessment, which is independent and incremental to that due to traditional CVRFs.

\section{Funding}

$\mathrm{NN}$ is funded by the Discovery Foundation and the Nuffield Trust. SN acknowledges support from the British Heart Foundation Centre of Research Excellence, Oxford. 
Table 1 Demographic, clinical and CMR features in SLE, SLE with CVRFs, controls and controls with CVRFs.

\begin{tabular}{cccccc}
\hline & Normal controls N=39 & Controls with CVRFs N=11 & SLE N=11 & SLE with CVRF N=19 & P Value \\
\hline Age (years) & $44.6 \pm 11.8$ & $51.7 \pm 8.9$ & $37.0 \pm 7.0$ & $46.7 \pm 10.7$ & 0.02 \\
\hline Females (\%) & $38(97.4)$ & $11(100)$ & $11(100)$ & $18(94.7)$ & 0.77 \\
\hline BMl $\left(\mathrm{kg} / \mathrm{m}^{2}\right)$ & $22.5 \pm 2.3$ & $27.5 \pm 5.2$ & $24.4 \pm 2.5$ & $30.5 \pm 6.4$ & $<0.001$ \\
\hline LVEDV $(\mathrm{ml})$ indexed to BSA & $76.6 \pm 12.1$ & $79.3 \pm 20.2$ & $80.7 \pm 16.1$ & $70.3 \pm 14.6$ & 0.22 \\
\hline LVESV $(\mathrm{ml})$ indexed to BSA & $21.1 \pm 5.4$ & $19.8 \pm 6.1$ & $23.0 \pm 10.5$ & $20.3 \pm 6.4$ & 0.66 \\
\hline LVEF & $72.5 \pm 4.1$ & $75.1 \pm 5.3$ & $72.6 \pm 7.3$ & $71.7 \pm 3.7$ & 0.27 \\
\hline LA size & $2.7 \pm 0.5$ & $2.9 \pm 0.5$ & $3.0 \pm 0.4$ & $3.3 \pm 0.6$ & $<0.001$ \\
\hline
\end{tabular}

BMI, Body mass index; LVEDV, Left ventricular end diastolic volume; BSA, Body surface area; LVESV, Left ventricular end systolic volume; LVEF, Left ventricular ejection fraction; LA, left atrium.

Table 2 Systolic circumferential strain, aortic distensibility and pulse wave velocity in SLE, SLE with CVRFs, controls and controls with CVRFs.

\begin{tabular}{|c|c|c|c|c|c|}
\hline & $\begin{array}{l}\text { Normal controls } \\
\mathrm{N}=39\end{array}$ & $\begin{array}{l}\text { Controls with } \\
\text { CVRFs } N=11 \\
\end{array}$ & SLE N=11 & $\begin{array}{l}\text { SLE with CVRF } \\
\quad \mathrm{N}=19\end{array}$ & P Value \\
\hline Mid SA systolic circumferential strain & $-19.4 \pm 1.1$ & $-18.4 \pm 1.4$ & $-16.7 \pm 1.2$ & $16.3 \pm 1.0$ & $<0.001$ \\
\hline Peak diastolic strain rate & $144.5 \pm 14.5$ & $126.9 \pm 20.7$ & $99.6 \pm 23.2$ & $89.4 \pm 17.3$ & $<0.001$ \\
\hline $\begin{array}{l}\text { Aortic distensibility }\left(10^{-3} \mathrm{mmHg}^{-1}\right) \text { Ascending aorta Proximal } \\
\text { descending aorta Distal descending aorta }\end{array}$ & $\begin{array}{l}3.6 \pm 2.04 .1 \pm \\
1.56 .2 \pm 2.5\end{array}$ & $\begin{array}{c}3.1 \pm 1.93 .4 \pm \\
1.74 .7 \pm 1.8\end{array}$ & $\begin{array}{l}3.2 \pm 1.13 .8 \pm \\
1.05 .0 \pm 1.2\end{array}$ & $\begin{array}{c}2.4 \pm 1.22 .8 \pm \\
1.03 .6 \pm 1.2\end{array}$ & $\begin{array}{c}0.110 .006 \\
<0.001\end{array}$ \\
\hline $\begin{array}{c}\text { Pulse wave velocity }(\mathrm{m} / \mathrm{s}) \text { Aortic arch PWV Descending aorta } \\
\text { PWV Total PWV }\end{array}$ & $\begin{array}{l}4.2 \pm 2.03 .7 \pm \\
1.54 .3 \pm 1.4\end{array}$ & $\begin{array}{l}5.5 \pm 1.95 .9 \pm \\
1.65 .4 \pm 2.4\end{array}$ & $\begin{array}{l}6.0 \pm 1.26 .6 \pm \\
1.66 .3 \pm 1.3\end{array}$ & $\begin{array}{r}7.5 \pm 2.18 .1 \\
\pm 1.78 .5 \pm 1.9\end{array}$ & $\begin{array}{l}<0.001 \\
<0.001 \\
<0.001\end{array}$ \\
\hline
\end{tabular}

SA, Short axis; PWV, pulse wave velocity.

The research was funded by an investigator-led grant from GSK.

\section{Author details}

${ }^{1}$ Cardiovascular Medicine, University of Oxford, Oxford, UK. ${ }^{2}$ GSK Clinical Imaging Centre, Imperial College, London, UK. ${ }^{3}$ Bortnar Institute and Nuffield Department of Orthopaedics, Rheumatology and Musculoskeletal Sciences, University of Oxford, Oxford, UK.

Published: 30 January 2013

Cite this article as: Ntusi et al:: Patients with systemic lupus

erythematosus have impaired strain and vascular function which is incremental to that caused by traditional risk factors: insights from

Cardiovascular Magnetic Resonance. Journal of Cardiovascular Magnetic

Resonance 2013 15(Suppl 1):E56.

Submit your next manuscript to BioMed Central and take full advantage of:

- Convenient online submission

- Thorough peer review

- No space constraints or color figure charges

- Immediate publication on acceptance

- Inclusion in PubMed, CAS, Scopus and Google Scholar

- Research which is freely available for redistribution 